Article

\title{
High-Quality Solid Fuel Production from Leaf Litter of Urban Street Trees
}

\author{
Nodirjon Nurmatov*, Daniel Armando Leon Gomez, Frank Hensgen, Lutz Bühle and \\ Michael Wachendorf
}

Department of Grassland Science and Renewable Plant Resources, University of Kassel, Steinstrasse 19, 37213 Witzenhausen, Germany; d.leongomez@stud.uni-goettingen.de (D.A.L.G.); hensgen@uni-kassel.de (F.H.); lutzbuehle@gmx.de (L.B.); mwach@uni-kassel.de (M.W.)

* Correspondence: gnr@uni-kassel.de; Tel.: +49-5542-98-1236; Fax: +49-5542-98-1230

Academic Editor: Barry D. Solomon

Received: 19 September 2016; Accepted: 24 November 2016; Published: 30 November 2016

\begin{abstract}
Leaf litter is a growing concern for cities. Due to adherent dirt such biomass is rarely utilized nowadays but may constitute a renewable energy source for communities or private households. Leaf litter from main roads, residential areas and city centres collected by the vacuum technique or the sweeper technique was sampled and analysed for ash content and chemical composition. Ash content of leaf litter collected by the sweeping technique was higher $(21.6 \%-40.1 \%$ dry matter, DM) than in material collected by the vacuum technique $(12.0 \%-21.7 \%$ DM). Leaf litter from residential areas had the highest contamination $(21.7 \%-40.1 \% \mathrm{DM})$, followed by main roads $(20.8 \%-26.2 \% \mathrm{DM})$ and city centres $(12.0 \%-21.6 \% \mathrm{DM})$. Ash content was reduced by up to $60 \%$ with a washing treatment and reached values comparable to those achieved by multiple manual rinsing, which was conducted as a reference treatment. The chemical composition of washed leaf litter could be further improved by mechanical dehydration treatment due to a reduction in harmful elements for combustion such as K, $\mathrm{Cl}, \mathrm{Mg}$ and $\mathrm{S}$. Heating value of leaf litter increased and the risk of corrosion and ash melting during combustion were reduced.
\end{abstract}

Keywords: bioenergy; combustion; leaf litter; city; street sweepings

\section{Introduction}

Trees are an increasing burden to city administrations, which have to dispose the autumn foliage. The disposal is not only cost-intensive but also an organisational challenge, as the EU legislation considers urban leaf litter to be waste once it is collected. Therefore, the waste hierarchy shall be applied, which defines actions to be taken in descending order of priority: prevention, preparing for re-use, recycling, other recovery, and disposal. Leaf litter is usually collected by municipalities for composting, burial or direct incineration [1]. Evidence of leaf litter use for energy production is scarce, as methane yields are low with conventional anaerobic digestion techniques [2], and abrasion during wet fermentation may occur because of soil adhesion [3]. Though combustion of leaf litter may be an efficient conversion process, ash concentration is a known problem, whether it is natural or caused by contamination due to collection, transport or storage. While leaf litter collected in urban parks showed average ash concentration of $13.8 \%$ dry matter (DM) [4] and 17.5\% DM [5], values can be as high as $34.8 \%$ DM when collected from street and pavement surfaces in practice [6]. Removal of ash after combustion is costly and the various ash fractions (bottom ash, cyclone fly-ash and filter fly ash constituting $60 \%-90 \%, 10 \%-35 \%$ and $2 \%-10 \%$, respectively, according to Van Loo and Koppejan [7]) need to be deposited or processed because of their content of hazardous elements (e.g., heavy metals, organic contaminants). Furthermore, ash slagging may cause damage in boilers [8] and increasing ash concentrations reduce the gross calorific value of biomass [9]. According to German standards, 
ash concentrations in fuels may not exceed certain limiting values, i.e., $1.0 \%-3.0 \%$ for wood chips, $1.5 \%-7.0 \%$ for wood pellets [10] and $4.0 \%-10.0 \%$ DM for pellets made from non-woody biomass to prevent impairment of combustion systems and the environment [11]. In addition to ash problems, several elements incorporated in non-woody biomass have severe negative effects if applied in the combustion process. It is mainly the higher proportions of potassium and magnesium in non-woody biomass that lead to problems of ash melting at lower temperatures, slagging and fouling, whereas the higher proportions of nitrogen and sulphur can lead to higher emissions $\left(\mathrm{NO}_{\mathrm{x}}, \mathrm{SO}_{2}\right)$, and the higher proportions of chlorine, sulphur and potassium lead to corrosion [12]. In addition, the relatively high ash concentration reduces the heating value of leaf litter.

Redirection of the present leaf litter waste stream to convert leaf litter into a high-quality solid fuel would be an appealing alternative. In contrast to incineration in a commercial waste treatment plant, which needs to be paid to accept waste, this would offer two main advantages to municipalities: leaf litter is converted from waste into a product, which could be sold and thereby reduce the costs for leaf litter removal; and autonomous energy is provided for local demand. The fuel could be burned in decentralised biomass boilers, e.g., in buildings, which might not be connected to district heating. This would require that the fuel characteristics of leaf litter are close to those of commonly used solid fuels and that they comply with the limiting values of the German regulations [11]. To reduce the mineral concentration in the fuel and to diminish the risk of corrosion and slagging, the IFBB (Integrated Generation of Solid Fuel and Biogas from Biomass) technique was suggested [13]. Its core procedure is mixing of biomass with warm water and subsequent mechanical dehydration. Thereby, a fibre-rich press cake and a press fluid are produced, the press fluid containing the main proportion of minerals. The feasibility of the technique is well investigated for grass of different origins including semi-natural material [14] and mixtures of semi-natural with urban biomass (e.g., lawn cut; [15]). First investigations with leaf litter showed that the effect of IFBB treatment on ash reduction was not as large as for grass material [4], so the authors considered introducing a washing step prior to dehydration to eliminate problems caused by soil particles adhering to leaf litter.

This paper aims to determine the effects of (i) provenience (main road, residential area, city centre); (ii) collecting techniques (road sweeper, vacuum device); (iii) washing (machine washing, manual washing) and (iv) mechanical dehydration on the ash and mineral concentration and the solid fuel quality in leaf litter, which was collected by the cleansing department of the city of Kassel through one full leaf litter fall period.

\section{Materials and Methods}

\subsection{Collection of Leaf Litter}

Collection of leaf litter was conducted in collaboration with the cleansing department of the city of Kassel. The city of Kassel is located in the middle of Germany and has about 200,000 inhabitants and an area of $107 \mathrm{~km}^{2}$. The leaf litter was collected from the ground in three city areas: (i) main roads (MRs); (ii) residential areas (RAs) and (iii) city centres (CCs). Areas differed in cleaning cycles: main roads were cleaned weekly, residential areas biweekly and the city centre was cleaned every second day. Two common large-scale collection techniques were applied: (i) the vacuum technique (VT) and (ii) the sweeping technique (ST), which were both mounted on municipal cleaning vehicles. The vacuum technique is appropriate for sites, which cannot be swept (e.g., parks, small greens along sideways) and where leaf litter is initially gathered with leaf blowers and subsequently picked up by a suction unit. The sweeping technique is usually applied on compacted surfaces and leaf litter is picked up with a rotating brush after moisturising. Leaf litter collection took place every second week at a collection point on the same day from 8 October to 10 December 2014, resulting in a total of 24 samples (4 sampling dates $\times 3$ proveniences $\times 2$ collection techniques). Due to the different cleaning cycles in the city, the time of ground contact of the samples differed between the city areas. Caused by the different durations of ground contact and climatic conditions, visual assessment of 
contamination already showed contrasts between the samples (Figure 1a-d). To conserve the samples for processing at a later stage they were filled into $60 \mathrm{~L}$ airtight polyethylene barrels, where ensiling took place. Ensiling lasted for at least 12 weeks.

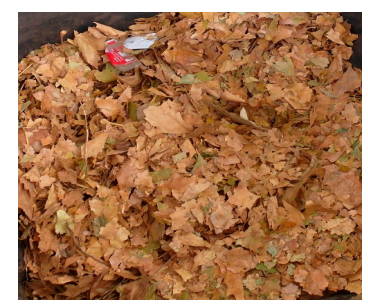

(a)

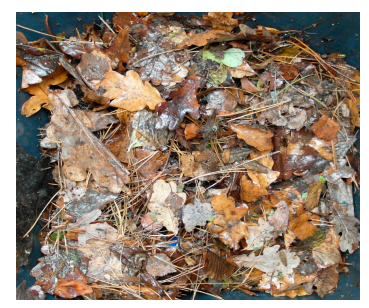

(b)

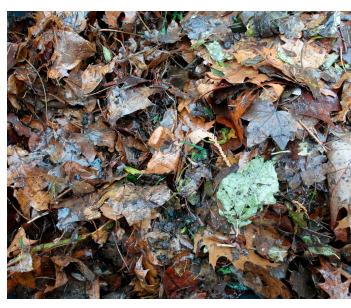

(c)

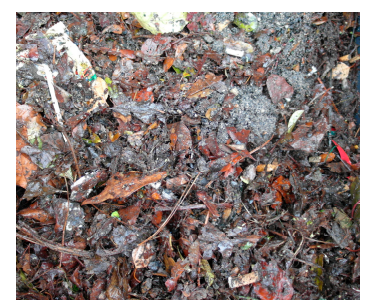

(d)

Figure 1. Exemplary display of leaf litter material immediately after collection by two different techniques: the vacuum technique in (a) residential areas during a dry period and (b) on main roads during a wet period; and the sweeping technique in (c) residential areas and (d) in city centres, both during a wet period.

\subsection{Washing Facility}

The washing facility used in the present study had measures of $100 \mathrm{~cm} \times 100 \mathrm{~cm} \times 60 \mathrm{~cm}$ (width $\times$ depth $\times$ height) with a sink in the lower part with a height of $40 \mathrm{~cm}$ (Figure 2a) as a sedimentation zone for dirt and waste that were removed after washing. Approximately $550 \mathrm{~L}$ of water were constantly swirled by pressing air through perforated pipes ( 7 pipes with 6 holes each with $4 \mathrm{~mm}$ diameter; Figure $2 \mathrm{~b}$ ) at the bottom of the tank using a side channel compressor (RICO Druckluftanlagenbau GmbH, Tönisvorst, Germany, $1.1 \mathrm{~kW}$, intake pressure 1000 mbar, rotational speed $2900 / \mathrm{min})$. A screen basket $(98 \mathrm{~cm} \times 98 \mathrm{~cm} \times 45 \mathrm{~cm}$, width $\times$ depth $\times$ height; Figure 2c) with a mesh size of $1.1 \mathrm{~cm}$ was inserted into the washing facility, where the ascending air bubbles (Figure 2d) broke up leaf litter clots and mobilized adhering dirt particles that sank through the sieve into the sedimentation area. The screen basket served to hold back leafy material, which could then be evacuated from the washing area.

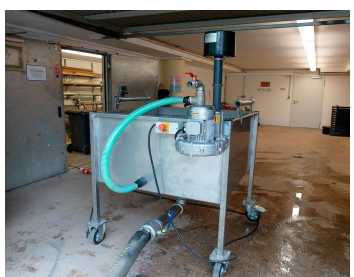

(a)

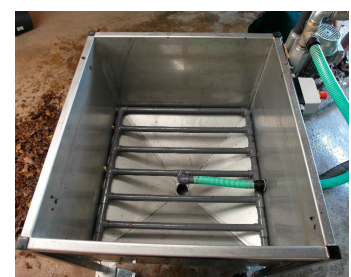

(b)

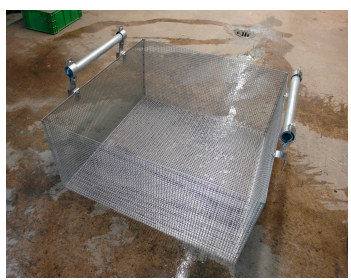

(c)

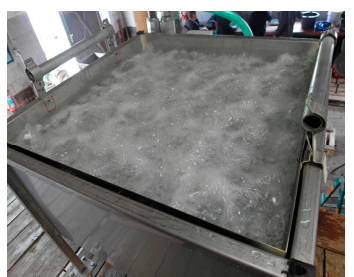

(d)

Figure 2. Foliage cleaning machine from the side (a); pipes and water outlet valve in the bottom (b); sieve basket (c) and in operation (d).

\subsection{Washing of Leaf Litter}

After evacuating the material from the plastic barrels, leaf litter clots were manually broken up and waste material (i.e., bottles, plastics, stones, wood, etc.) was removed. Depending on water content and degree of contamination, approximately 3 to $10 \mathrm{~kg}$ leaf litter was used for washing. An additional sample of $400 \mathrm{~g}$ was taken for determination of dry matter and ash content and elemental composition. Machine washing was conducted for $5 \mathrm{~min}$ at a water temperature of 10 to $12{ }^{\circ} \mathrm{C}$.

Three kilograms of leaf litter were used for manual washing, which was assumed to represent a completely purified material and, thus, to establish a point of reference to determine the effectiveness of the machine washing. This material was stored in a freezer at $-18{ }^{\circ} \mathrm{C}$ for 12 weeks. After defrosting, 
samples were thoroughly mixed and consecutively rinsed in 4 plastic barrels filled with fresh water at room temperature.

\subsection{Mechanical Dehydration}

The washed material was further processed by mechanical separation with a screw press (type AV, Anhydro Ltd., Kassel, Germany). The conical screw had a pitch of 1:6 and a rotational speed of 6 revolutions $\mathrm{min}^{-1}$. The cylindrical screen encapsulating the screw had a perforation of $1.5 \mathrm{~mm}$. The press fluid was discarded; the press cake was sampled for further analysis.

\subsection{Laboratory Analysis of Leaf Litter}

Samples for dry matter analysis were taken from the raw material, manually washed and pressed material and dried at $105^{\circ} \mathrm{C}$ in a drying oven for ash and DM determination. Samples were ground with a cutting mill (Retsch, Haan, Germany, Type SM-100, motor type: AEG 1.5 Kw, rotational speed 1400 revolutions $\mathrm{min}^{-1}$ ) to pass a $4 \mathrm{~mm}$ sieve. Samples were incinerated in a muffle furnace at $550{ }^{\circ} \mathrm{C}$ to determine the ash content. A second set of samples was taken for elemental composition analysis and dried at $60{ }^{\circ} \mathrm{C}$ for $48 \mathrm{~h}$. These samples were also ground to $4 \mathrm{~mm}$ with the same cutting mill and then further processed with sample mill (1093 Cyclotec, Foss GmbH, Hamburg, Germany) to $1 \mathrm{~mm}$. $\mathrm{C}, \mathrm{H}$ and $\mathrm{N}$ concentrations in samples were determined with an elemental analyser (Vario Max CHN Elementar Analysesysteme $\mathrm{GmbH}$, Hanau, Germany,). Content of $\mathrm{K}, \mathrm{Na}, \mathrm{Mg}, \mathrm{Ca}, \mathrm{Cl}, \mathrm{S}$ and $\mathrm{P}$ were determined by X-ray fluorescence analysis by an external laboratory (Landesbetrieb Landwirtschaft Hessen, Kassel, Germany).

\subsection{Calculations}

The higher heating value (HHV) was calculated based on the concentrations of $\mathrm{C}, \mathrm{H}$, and $\mathrm{N}$ $\left[\mathrm{g} \cdot \mathrm{kg}^{-1} \mathrm{DM}\right.$ ] using the Equation (1) for bio-fuels by Friedl et al. [16]:

$$
\mathrm{HHV}\left[\mathrm{MJ} \cdot \mathrm{kg}^{-1} \mathrm{DM}\right]=3.55 \times \mathrm{C}^{2}-232 \times \mathrm{C}-2230 \times \mathrm{H}+51.2 \times \mathrm{C} \times \mathrm{H}+131 \times \mathrm{N}+20,600
$$

Ash softening temperature (AST) was calculated on the basis of the concentrations of $\mathrm{Ca}, \mathrm{Mg}$ and $\mathrm{K}\left[\mathrm{g} \cdot \mathrm{kg}^{-1} \mathrm{DM}\right]$ according to the formula by Hartmann [17], as equation (2):

$$
\operatorname{AST}\left[\mathrm{C}^{\circ}\right]=1172-5.39 \times \mathrm{K}+25.27 \times \mathrm{Ca}-78.84 \times \mathrm{Mg}
$$

\subsection{Statistical Analysis}

Statistical analyses were conducted applying the R software (Version 3.0.2., R Foundation for Statistical Computing, Vienna, Austria) [18]. Because the assumptions to conduct an analysis of variance (ANOVA) were not given, non-parametric alternatives had to be applied. The non-parametric Kruskal-Wallis test with the post hoc function "kruskalmc" was used if more than three factor levels were given in order to determine significant differences in the ash content, mineral composition, higher heating value, ash softening temperature and indices among locations (main road, residential area, city centre) and materials (unwashed, machine washed, manually washed, press cake). A non-parametric Wilcoxon signed rank test was performed to test for significant differences in ash content, mineral composition, higher heating value, ash softening temperature and indices caused by collection techniques with two factor levels (the vacuum technique and the sweeper technique).

\section{Results and Discussion}

\subsection{Chemical Composition and Fuel Properties of Leaf Litter}

According to visual and olfactory assessment, the ensiling process of the material was successful. As shown by Piepenschneider et al. [4], ensiling of leaf litter on a laboratory scale (30-60 L polyethylene 
barrels) is possible in principle, provided that adequate compaction, air-tight closure and storage under cool and dark conditions is applied. Mineral and ash concentration of the parent material over all collection techniques and proveniences differed widely, shown by high standard deviations (Table 1, Table A1). In comparison to leaves collected by hand in a park area of the city of Kassel [19], the measured values for $\mathrm{S}, \mathrm{Mg}, \mathrm{Na}, \mathrm{Cl}$ and ash were considerably higher. This might be explained by a higher contamination with soil and dirt particles due to the location and technique of collection, especially in the case of $\mathrm{Na}$ and $\mathrm{Cl}$ by contamination due to salt application for de-icing streets in autumn and winter time. Clean forest leaf litter investigated by Tyler [20] in a southern Swedish natural beech forest undisturbed for at least 50 years, collected with nets above ground, showed lower values for all elements but still an inherent level of ash of $5.28 \% \mathrm{DM}$. The ash concentration and mineral composition in a high quality standard fuel such as beech wood is significantly lower, with total ash values around $0.5 \%$ DM. From the chemical composition of our samples and the literature values, we calculated two indices. The $\mathrm{K}_{2} \mathrm{O} / \mathrm{CaO}$ Index proposed by Bühle et al. [21] serves as a measure for the risk of ash melting at low temperature. The lower the index, the lower the risk of ash melting at low temperatures. Due to the relatively high concentrations of $\mathrm{Ca}$ in the autumn foliage, the risk of low ash melting temperatures is very low in all leaf fractions, even lower than in beech wood. Nevertheless, the complex topic of ash melting behaviour of biomass fuels cannot be precisely predicted with a simple index involving only $\mathrm{Ca}$ and $\mathrm{K}$, as several studies have shown [21,22]. Thus, further laboratory research is needed. The other index, the $2 \mathrm{~S} / \mathrm{Cl}$ ratio, assesses the risk of high-temperature corrosion. According to Sommersacher et al. [23] and Khalsa et al. [5], the value should be $\geq 4$ for a minor risk of corrosion, or $>8$ in order to rule out any corrosion risk. While the literature value for beech wood is $>4$, values for leaves are below this threshold due to high $\mathrm{Cl}$ concentrations. Thus, corrosion is likely to appear if untreated leaves are combusted. High corrosion risk has also been reported for untreated leaf litter collected in an urban park area in the city of Munich [5].

Table 1. Mineral and ash concentration (\% dry matter) and two indices with relevance for ash melting behaviour $\left(\mathrm{K}_{2} \mathrm{O} / \mathrm{CaO}\right)$ and corrosion risk $(2 \mathrm{~S} / \mathrm{Cl})$ in leaves from different origins compared with beech wood.

\begin{tabular}{|c|c|c|c|c|c|}
\hline Element/Index & Unit & City Leaves ${ }^{1}$ & Park Leaves ${ }^{2}$ & Forest Leaves $^{3}$ & Beech Wood ${ }^{4}$ \\
\hline $\mathrm{S}$ & {$[\% \mathrm{DM}]^{7}$} & $0.15 \pm 0.04$ & 0.08 & 0.08 & 0.02 \\
\hline $\mathrm{Ca}$ & {$[\% \mathrm{DM}]$} & $2.87 \pm 0.62$ & 2.17 & 0.87 & 0.29 \\
\hline $\mathrm{Mg}$ & [\% DM] & $0.54 \pm 0.36$ & 0.30 & 0.12 & 0.04 \\
\hline $\mathrm{Na}$ & {$[\% \mathrm{DM}]$} & $0.13 \pm 0.12$ & 0.03 & 0.01 & - \\
\hline $\mathrm{P}$ & [\% DM] & $0.14 \pm 0.04$ & 0.14 & 0.07 & 0.04 \\
\hline K & {$[\% \mathrm{DM}]$} & $0.64 \pm 0.16$ & 0.62 & 0.25 & 0.15 \\
\hline $\mathrm{Cl}$ & {$[\% \mathrm{DM}]$} & $0.30 \pm 0.25$ & 0.05 & - & 0.01 \\
\hline Ash & {$[\% \mathrm{DM}]$} & $23.73 \pm 10.55$ & 13.80 & 5.28 & 0.5 \\
\hline $\mathrm{K}_{2} \mathrm{O} / \mathrm{CaO}^{5}$ & & 0.192 & 0.246 & 0.25 & 0.45 \\
\hline $2 \mathrm{~S} / \mathrm{Cl}^{6}$ & & 1.10 & 3.55 & - & 5.54 \\
\hline
\end{tabular}

Ash content in leaf litter originating from the city centre was lowest $(16.8 \%$ of DM) and differed significantly from the residential area material (30.9\% of DM) (Figure 3). Leaf litter from the main roads showed an ash content in between the other two proveniences $(23.5 \%$ of DM). The collection technique also had a significant effect with a lower ash content for leaf litter collected with vacuum technique $(18.2 \%$ of DM), while the use of a road sweeper increased ash content by an additional $10 \%$ of DM on average.

Machine and manual washing significantly reduced ash content by $13 \%$ of DM compared to the parent material, and both washing processes achieved similar values $(10.4 \%$ and $10.2 \%$ of DM for machine and manual washing, respectively), showing that machine washing was as effective as hand 
washing. No further reduction of total ash could be achieved by mechanical dehydration of machine washed leaf litter (Figure 3). Ash content after washing was close to the threshold for solid fuels from non-woody biomasses, as defined by the German standard (10\% DM, [11]).

Except for $\mathrm{K}$, provenience of leaf litter material had a significant effect on its chemical composition (Figure 4a). Similar to its higher ash content, the residential area had higher content of $\mathrm{Ca}, \mathrm{Mg}, \mathrm{Na}$ and $\mathrm{P}$, while content of $\mathrm{S}$ and $\mathrm{Cl}$ were lower than in material from the city centre and litter from the main road showed intermediate content. Although the collecting technique had an effect on overall ash content, the effect on the investigated elements was most often not statistically significant (Figure $4 \mathrm{~b}$ ) —only in the case of $\mathrm{Na}$, where values for the vacuum technique were half the values for the suction technique. The washing treatment and the subsequent mechanical dehydration on the other hand did have a remarkable cleaning effect for all elements except $\mathrm{Ca}$ (Figure 4c).

The machine washed leaf material had significantly reduced values for $\mathrm{Mg}, \mathrm{Na}, \mathrm{P}, \mathrm{K}$ and $\mathrm{Cl}$ in comparison to the freshly collected leaf litter. The comparison between washed material (MW) and washed and pressed material (PC) revealed that the PC had lower values in all cases, but statistical significance was only given in the case of P. In addition, it could be observed that the variability between the samples was much lower in the PC than in the MW or UM samples, which means that the additional treatment of mechanical dehydration leads to a homogenization of the chemical composition of such heterogeneous materials. However, the washed material needs drying, if it is to be used as a fuel. By mechanical dehydration, the washed material can be dried up to DM concentrations of $50 \%$ in an efficient manner, thus the overall energy efficiency of the IFBB system is comparable to direct biomass combustion, as has been shown by Bühle et al. [24] and Hensgen et al. [15]. Leaf litter is not the only residual biomass in a city which could be used for energy conversion. Hensgen et al. [15] have shown that urban green cuts from private gardens and communal greens can also be used as a fuel after pre-treatment according to the IFBB. If a city administration should think of a system for utilising green and wood-like residual biomass and leaf litter alike, the proposed system of washing and mechanical dehydration seems to be a suitable solution to produce a solid fuel for combustion.

Piepenschneider et al. [4] and Khalsa et al. [5] also investigated the effect of washing and mechanical separation on the mineral concentrations of urban leaf litter for combustion. It can be stated that the mineral concentrations found in MW and PC material is in the range of their results, indicating that the washing step worked with the same efficiency and the minerals in the MW and PC material are those, which are inherent to the leaf litter material. In comparison to beech wood as a standard fuel, there are higher concentrations of $\mathrm{S}$ and $\mathrm{Cl}$ as well as $\mathrm{K}, \mathrm{Ca}$ and $\mathrm{Mg}$ in treated leaf litter. However, the concentrations in leaf litter have been reduced near to or even below the guiding thresholds for unproblematic combustion stated by Obernberger et al. [12].

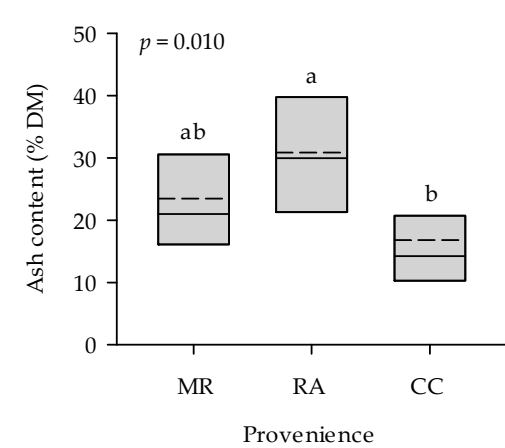

(a)

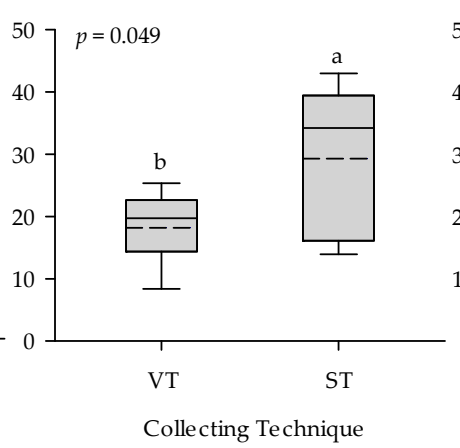

(b)

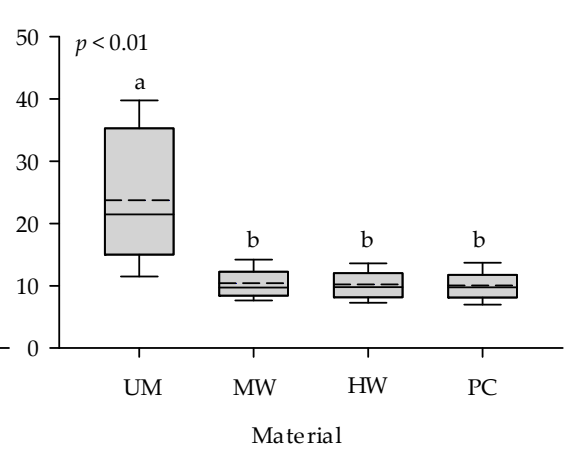

(c)

Figure 3. Ash content of leaf litter from (a) proveniences (main roads-MRs, residential areas-RAs, city centres-CCs) collected by (b) the vacuum technique (VT) or the sweeper technique (ST); and (c) ash content of materials after different treatments (unwashed-UM, machine washed-MW, hand washed-HW, press cake-PC). Dashed lines indicate the arithmetic mean and solid lines indicate the median. Different letters indicate significant differences. 

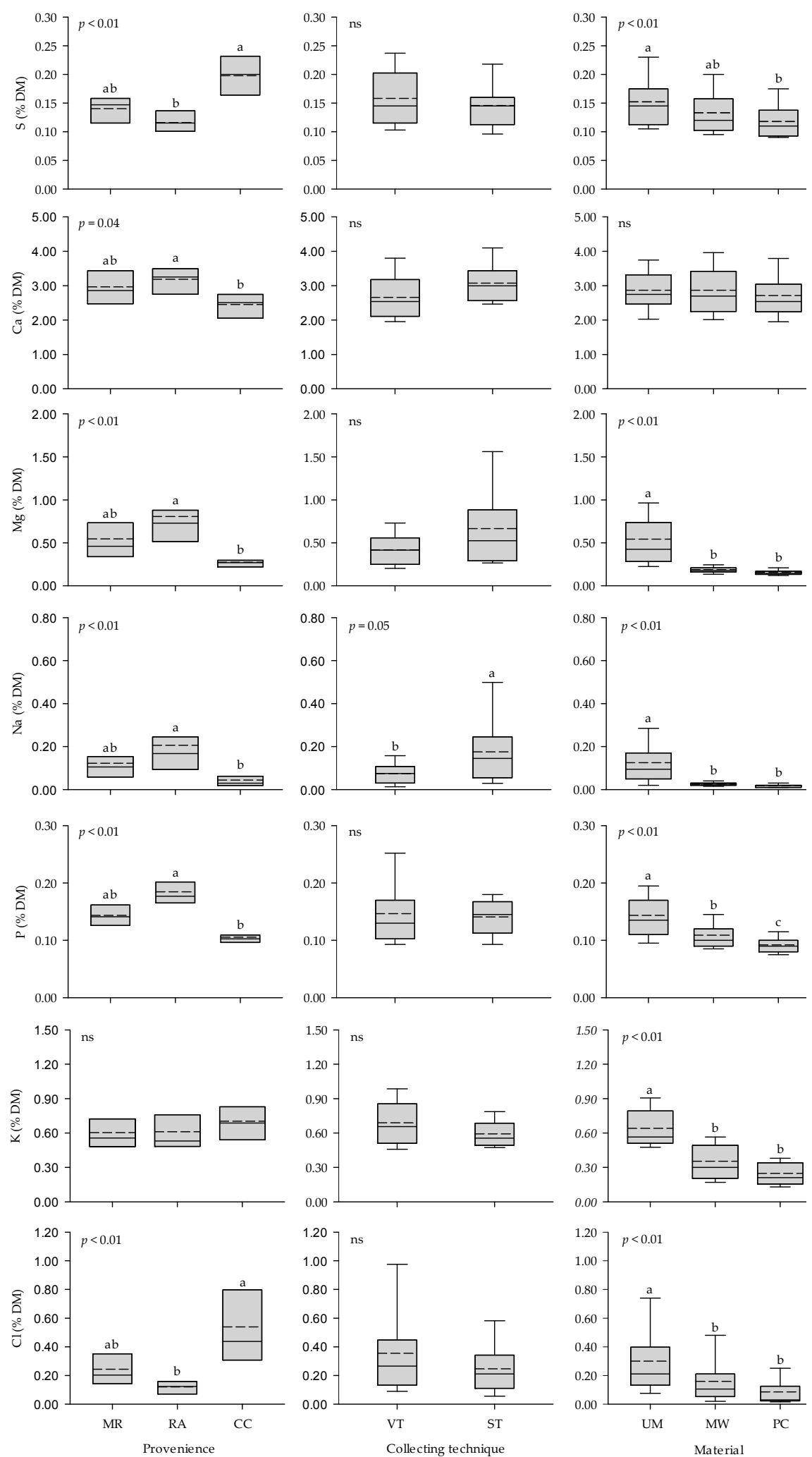

Figure 4. Content of $\mathrm{S}, \mathrm{Ca}, \mathrm{Mg}, \mathrm{Na}, \mathrm{P}, \mathrm{K}$ and $\mathrm{Cl}$ (\% dry matter) in leaf litter from (a) various proveniences (main road-MR, residential area-RA, city centre-CC) collected by (b) different techniques (vacuum technique-VT and Sweeper technique-ST); The effect of different treatments is shown in (c) (unwashed-UM, machine washed-MW, press cake-PC). Whiskers indicate the 5th and 95th percentiles. Dashed lines indicate mean and solid lines indicate median values. Different letters indicate significant differences among, ns—not significant. 


\subsection{Heating Value}

The calculated HHV of leaf litter showed significant differences between the proveniences (Figure 5), with highest values for the city centres $\left(18.21 \mathrm{MJ} \cdot \mathrm{kg}^{-1} \mathrm{DM}\right)$ and lowest values for the residential areas $\left(16.21 \mathrm{MJ} \cdot \mathrm{kg}^{-1} \mathrm{DM}\right)$ and intermediate values for the main roads $\left(16.87 \mathrm{MJ} \cdot \mathrm{kg}^{-1} \mathrm{DM}\right)$. This is caused by the higher value of $C$ in city centre leaf litter, which again might be due to the faster collection cycle, providing less time for the leaf material to decompose on the ground before collection and the lower value of ash in the samples of the city centre. HHV for material collected by the sweeping technique $\left(16.35 \mathrm{MJ} \cdot \mathrm{kg}^{-1} \mathrm{DM}\right)$ was lower than values for the material collected by the vacuum technique (17.84 MJ $\left.\cdot \mathrm{kg}^{-1} \mathrm{DM}\right)$. This may be explained by the higher ash content of the material collected by the sweeping machine.

Washing had a positive effect on HHV with an average increase from 17.10 to $19.12 \mathrm{MJ} \cdot \mathrm{kg}^{-1} \mathrm{DM}$, which was mainly due to the reduction in ash content. Contrarily, mechanical dehydration did not lead to an additional increase. $\mathrm{N}$ concentration in the leaf litter material was below $1.0 \% \mathrm{DM}$; however, washing or mechanical dehydration did not reduce it further. Values for UM, MW and PC were above the threshold value of $0.6 \% \mathrm{DM}$, as proposed by Obernberger et al. [12] for an unproblematic combustion process considering $\mathrm{NO}_{\mathrm{x}}$ emissions. Thus, technical measures such as air staging are necessary to prevent $\mathrm{NO}_{\mathrm{x}}$ emissions in combustion $[25,26]$.

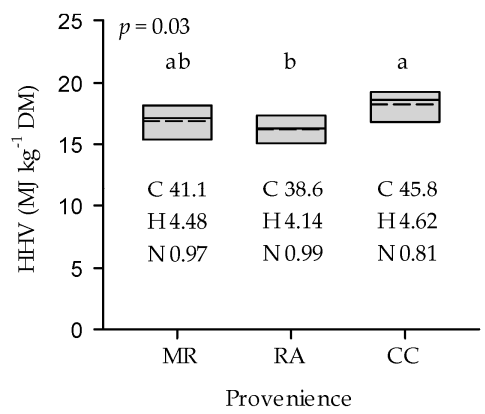

(a)

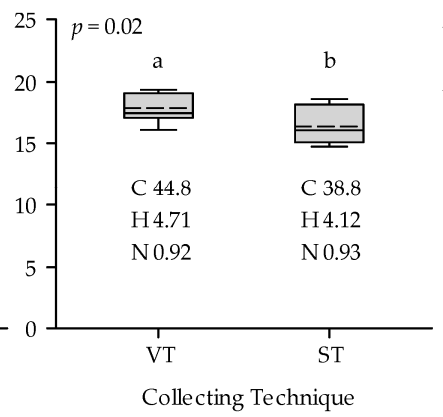

(b)

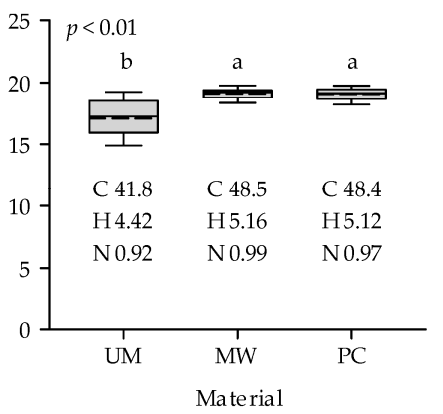

(c)

Figure 5. Higher heating value (HHV; $\mathrm{MJ} \cdot \mathrm{kg}^{-1} \mathrm{DM}$ ) of leaf litter from (a) different proveniences (main roads-MRs, residential areas-RAs, city centres-CCs) collected by (b) the vacuum technique (VT) or the sweeper technique (ST); (c) HHV after different treatments (unwashed-UM, machine washed-MW, press cake-PC). Dashed lines indicate the arithmetic mean and solid lines indicate the median. Different letters indicate significant differences.

\subsection{Ash Softening Temperature}

Ash softening temperature (AST) of the parent material was high (ca. $1500^{\circ} \mathrm{C}$ ), which was caused by high Ca concentrations, and no differences were found among proveniences or collection techniques (Figure 6a,b). Washing and mechanical dehydration increased AST further to around $1700{ }^{\circ} \mathrm{C}$, as the relative reduction of $\mathrm{Ca}$ in the fuel was lower than that of $\mathrm{K}$ and $\mathrm{Mg}$. However, as these are only calculated values, further research is necessary on the effect of washing and mechanical dehydration on leaf litter. Khalsa et al. [5] carried out combustion experiments with treated leaf litter (washing and mechanical leaching) and found a surprisingly low ash shrinkage starting temperature of $950{ }^{\circ} \mathrm{C}$, but deformation-, hemisphere- and flow temperatures were also above $1500^{\circ} \mathrm{C}$. Piepenschneider et al. [4] investigated park leaves of five manually collected genera and measured AST both in raw leaves and in IFBB treated leaves. The mean measured AST for the untreated material was $1233^{\circ} \mathrm{C}$, whereas it was $1245^{\circ} \mathrm{C}$ for the IFBB PC. This marginal difference might be, on the one hand, due to the different provenience and collection techniques, as the park leaf material was comparably clean with only low amounts of adherent soil. Thus, washing and mechanical dehydration could not wash out the same amount of minerals responsible for ash melting. On the other hand, the adaptation of the IFBB system proposed in our actual study, i.e., the replacement of the mashing step of the conventional IFBB 
with a washing step, where the washing water is separated and omitted seems to be more efficient in removing soil and minerals. For the pre-treated leaf litter, AST is on a high level and comparable to wood [17]; therefore, ash slagging and fouling is unlikely to occur.

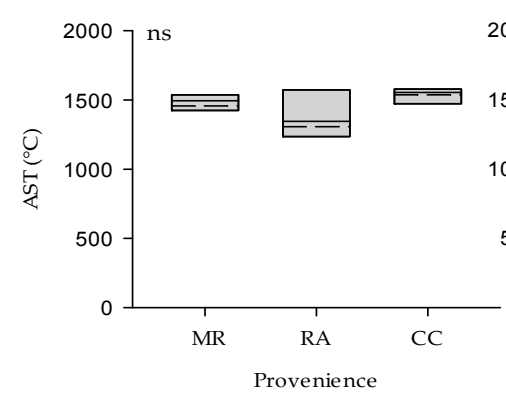

(a)

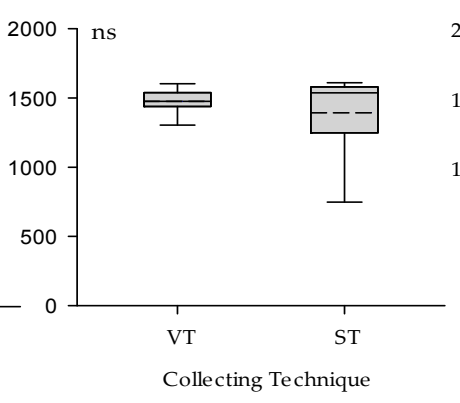

(b)

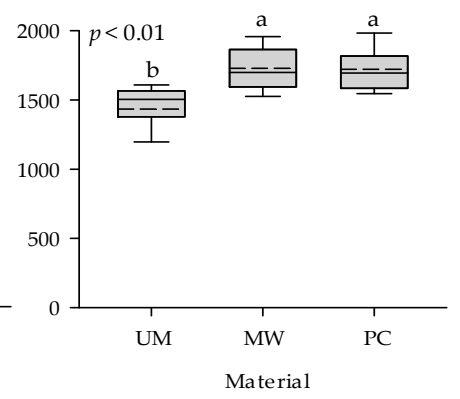

(c)

Figure 6. Ash softening temperature (AST; ${ }^{\circ} \mathrm{C}$ ) of leaf litter from (a) different proveniences (main roads-MRs, residential areas-RAs, city centres-CCs) collected by (b) the vacuum technique (VT) or the sweeper technique (ST); (c) ash softening temperature after different treatments (unwashed-UM, machine washed-MW, press cake-PC). Dashed lines indicate the arithmetic mean and solid lines indicate the median. Different letters indicate significant differences, ns—not significant.

\subsection{Indices}

The $\mathrm{K}_{2} \mathrm{O} / \mathrm{CaO}$ index according to Bühle et al. [21] was calculated to estimate the slagging and fouling tendencies of the materials. There was a significant effect for provenience and material, but not for collecting technique (Table 2). The material from the residential area had a lower $\mathrm{K}_{2} \mathrm{O} / \mathrm{CaO}$ ratio, meaning that these samples are less likely to cause problems with ash slagging or fouling. However, values were generally low for all proveniences and were still reduced by washing and mechanical dehydration (from 0.20 to 0.09 ). The results confirmed earlier results on park leaf material by Piepenschneider et al. [4], where a reduction of the $\mathrm{K}_{2} \mathrm{O} / \mathrm{CaO}$ index from 0.25 to 0.15 was found with the conventional IFBB treatment. Though the study by Khalsa et al. [5] used a different index to predict problems with ash melting during combustion $((\mathrm{Si}+\mathrm{P}+\mathrm{K}) /(\mathrm{Ca}+\mathrm{Mg}))$, they also showed that the washing and mechanical leaching treatment significantly reduced the risk of ash melting of leaf litter and nearly reached the value for wood pellets according to the European and German standard [10]. These findings together with the calculated AST indicate a very low risk of ash melting problems in combustion for such fuels.

Table 2. Mean values of $\mathrm{K}_{2} \mathrm{O} / \mathrm{CaO}$ and $2 \mathrm{~S} / \mathrm{Cl}$ index for leaf litter of different origins, collecting techniques and treatment steps.

\begin{tabular}{|c|c|c|c|c|c|c|c|}
\hline \multirow{2}{*}{ Variable } & \multirow{2}{*}{$n$} & \multicolumn{3}{|c|}{$\mathrm{K}_{2} \mathrm{O} / \mathrm{CaO}$} & \multicolumn{3}{|c|}{$2 \mathrm{~S} / \mathrm{Cl}$} \\
\hline & & Mean & Group & $p$-Value & Mean & Group & $p$-Value \\
\hline \multicolumn{8}{|l|}{ Provenience } \\
\hline Main road & 8 & 0.18 & $a b$ & 0.04 & 1.58 & $a b$ & 0.002 \\
\hline Residential area & 8 & 0.16 & $\mathrm{~b}$ & & 2.49 & $\mathrm{a}$ & \\
\hline City centre & 8 & 0.27 & a & & 0.94 & $\mathrm{~b}$ & \\
\hline \multicolumn{8}{|l|}{ Collecting technique } \\
\hline Vacuum technique & 12 & 0.24 & a & ns & 1.52 & $\mathrm{a}$ & $\mathrm{ns}$ \\
\hline $\begin{array}{l}\text { Sweeper technique } \\
\text { Material }\end{array}$ & 12 & 0.18 & a & & 1.87 & a & \\
\hline Unwashed material & 24 & 0.20 & a & $<0.01$ & 1.67 & $\mathrm{~b}$ & $<0.01$ \\
\hline Machine washed & 24 & 0.12 & $\mathrm{~b}$ & & 4.24 & a & \\
\hline Press cake & 24 & 0.09 & $\mathrm{~b}$ & & 7.08 & a & \\
\hline
\end{tabular}


The $2 \mathrm{~S} / \mathrm{Cl}$ index for the untreated materials indicated a high risk of corrosion (values below 2 [23]) for untreated leaf litter materials. However, there was a significant effect of provenience with highest values and therefore lowest corrosion risk for residential area material and highest corrosion risk for material from the city centre. The washing and mechanical dehydration led to a significant improvement with values between 4 and 8 . This is due to the high wash out rate of $\mathrm{Cl}$, which is relatively higher than that of S [14].

\section{Conclusions}

By investigating leaf litter from a full season of leaf fall, provenience was found to affect the properties of leaf litter for energetic conversion. Material collected in the city centre showed lower overall ash content and lower concentrations of specific minerals such as $\mathrm{Ca}, \mathrm{Mg}, \mathrm{Na}$ and $\mathrm{P}$ than the material collected in residential areas, but higher $\mathrm{Cl}$ concentrations. The city centre materials had higher heating values but also a higher risk of corrosion. These differences are attributed to the different cleaning cycles in the city, defining the time of ground contact for leaf litter. Collection techniques also proved significant, with leaf litter collected with the vacuum device showing lower ash and $\mathrm{Na}$ content and a higher heating value compared to material collected with the sweeper technique. The washing of leaf litter resulted in significantly reduced ash and element concentrations, and, thus, increased heating value as well as ash softening temperature and a lowered corrosion risk. Mechanical dehydration after machine washing did not lead to an additional substantial reduction in ash or mineral concentration of solid fuels obtained.

Acknowledgments: The authors are grateful for receiving funding from the European Union through the Interreg IV B regional development fund for the COMBINE Project (No. 299J) and from the German Academic Exchange Service (DAAD).

Author Contributions: Nodirjon Nurmatov carried out the experiment at all stages and is the main author of the manuscript. Daniel Armando Leon Gomez performed the manual washing experiment and contributed to the Material and Methods section. Frank Hensgen designed and supervised the experiments and contributed to the Results and Discussion sections. Lutz Bühle designed and supervised the construction of the washing machine and contributed to the Discussion section. Michael Wachendorf supervised the study design and manuscript preparation.

Conflicts of Interest: The authors declare no conflict of interest. 


\section{Appendix A}

Table A1. Mean values \pm standard deviation of mineral elements in different leaf litter material (unwashed, machine washed, press cake) sampled by two collecting devices (vacuum device, street sweeper) from three different city areas (main roads, residential areas, city centres).

\begin{tabular}{|c|c|c|c|c|c|c|c|}
\hline \multirow{3}{*}{ Element } & \multirow{3}{*}{ Technique/Material } & \multicolumn{2}{|c|}{ Main Road } & \multicolumn{2}{|c|}{ Residential Area } & \multicolumn{2}{|c|}{ City Centre } \\
\hline & & Vacuum Technique & Sweeping Technique & Vacuum Technique & Sweeping Technique & Vacuum Technique & Sweeping Technique \\
\hline & & $\% \mathrm{DM}$ & $\% \mathrm{DM}$ & $\% \mathrm{DM}$ & $\% \mathrm{DM}$ & $\% \mathrm{DM}$ & $\% \mathrm{DM}$ \\
\hline \multirow{3}{*}{ S } & Unwashed & $0.14 \pm 0.02$ & $0.14 \pm 0.02$ & $0.12 \pm 0.02$ & $0.11 \pm 0.02$ & $0.22 \pm 0.03$ & $0.18 \pm 0.03$ \\
\hline & Machine washed & $0.12 \pm 0.03$ & $0.13 \pm 0.01$ & $0.10 \pm 0.02$ & $0.11 \pm 0.02$ & $0.18 \pm 0.04$ & $0.16 \pm 0.03$ \\
\hline & Press cake & $0.10 \pm 0.01$ & $0.11 \pm 0.00$ & $0.09 \pm 0.01$ & $0.10 \pm 0.02$ & $0.16 \pm 0.02$ & $0.14 \pm 0.03$ \\
\hline \multirow{3}{*}{$\mathrm{Ca}$} & Unwashed & $2.96 \pm 0.76$ & $2.97 \pm 0.50$ & $2.84 \pm 0.60$ & $3.53 \pm 0.60$ & $2.19 \pm 0.28$ & $2.72 \pm 0.26$ \\
\hline & Machine washed & $3.01 \pm 0.85$ & $2.91 \pm 0.45$ & $2.92 \pm 0.71$ & $3.64 \pm 0.40$ & $2.23 \pm 0.32$ & $2.52 \pm 0.42$ \\
\hline & Press cake & $3.09 \pm 0.82$ & $2.79 \pm 0.52$ & $2.76 \pm 0.49$ & $3.29 \pm 0.58$ & $2.10 \pm 0.24$ & $2.26 \pm 0.40$ \\
\hline \multirow{3}{*}{$\mathrm{Mg}$} & Unwashed & $0.50 \pm 0.19$ & $0.59 \pm 0.32$ & $0.53 \pm 0.11$ & $1.08 \pm 0.47$ & $0.23 \pm 0.04$ & $0.32 \pm 0.07$ \\
\hline & Machine washed & $0.20 \pm 0.10$ & $0.18 \pm 0.03$ & $0.20 \pm 0.05$ & $0.19 \pm 0.03$ & $0.19 \pm 0.03$ & $0.17 \pm 0.05$ \\
\hline & Press cake & $0.17 \pm 0.07$ & $0.14 \pm 0.02$ & $0.18 \pm 0.03$ & $0.15 \pm 0.03$ & $0.15 \pm 0.02$ & $0.14 \pm 0.03$ \\
\hline \multirow{3}{*}{$\mathrm{Na}$} & Unwashed & $0.09 \pm 0.03$ & $0.16 \pm 0.11$ & $0.11 \pm 0.04$ & $0.30 \pm 0.19$ & $0.02 \pm 0.01$ & $0.07 \pm 0.04$ \\
\hline & Machine washed & $0.02 \pm 0.00$ & $0.03 \pm 0.01$ & $0.02 \pm 0.00$ & $0.03 \pm 0.01$ & $0.02 \pm 0.00$ & $0.02 \pm 0.01$ \\
\hline & Press cake & $0.02 \pm 0.00$ & $0.02 \pm 0.01$ & $0.02 \pm 0.01$ & $0.02 \pm 0.01$ & $0.01 \pm 0.00$ & $0.02 \pm 0.01$ \\
\hline \multirow{3}{*}{$\mathrm{P}$} & Unwashed & $0.15 \pm 0.02$ & $0.14 \pm 0.02$ & $0.19 \pm 0.06$ & $0.17 \pm 0.01$ & $0.10 \pm 0.01$ & $0.11 \pm 0.02$ \\
\hline & Machine washed & $0.10 \pm 0.02$ & $0.11 \pm 0.01$ & $0.13 \pm 0.05$ & $0.11 \pm 0.01$ & $0.10 \pm 0.01$ & $0.10 \pm 0.01$ \\
\hline & Press cake & $0.09 \pm 0.02$ & $0.09 \pm 0.01$ & $0.11 \pm 0.03$ & $0.10 \pm 0.01$ & $0.08 \pm 0.01$ & $0.08 \pm 0.01$ \\
\hline \multirow{3}{*}{ K } & Unwashed & $0.59 \pm 0.18$ & $0.61 \pm 0.12$ & $0.69 \pm 0.23$ & $0.53 \pm 0.06$ & $0.78 \pm 0.19$ & $0.63 \pm 0.13$ \\
\hline & Machine washed & $0.28 \pm 0.11$ & $0.30 \pm 0.11$ & $0.33 \pm 0.16$ & $0.22 \pm 0.10$ & $0.60 \pm 0.17$ & $0.40 \pm 0.13$ \\
\hline & Press cake & $0.20 \pm 0.08$ & $0.19 \pm 0.08$ & $0.26 \pm 0.10$ & $0.16 \pm 0.04$ & $0.39 \pm 0.08$ & $0.28 \pm 0.09$ \\
\hline \multirow{3}{*}{$\mathrm{Cl}$} & Unwashed & $0.26 \pm 0.10$ & $0.23 \pm 0.17$ & $0.12 \pm 0.03$ & $0.12 \pm 0.07$ & $0.69 \pm 0.30$ & $0.39 \pm 0.17$ \\
\hline & Machine washed & $0.09 \pm 0.04$ & $0.11 \pm 0.08$ & $0.04 \pm 0.02$ & $0.05 \pm 0.04$ & $0.43 \pm 0.23$ & $0.23 \pm 0.13$ \\
\hline & Press cake & $0.05 \pm 0.02$ & $0.04 \pm 0.04$ & $0.03 \pm 0.01$ & $0.02 \pm 0.01$ & $0.23 \pm 0.09$ & $0.15 \pm 0.10$ \\
\hline \multirow{4}{*}{ Ash } & Unwashed & $20.78 \pm 4.70$ & $26.19 \pm 11.00$ & $21.72 \pm 1.76$ & $40.04 \pm 3.26$ & $12.02 \pm 4.08$ & $21.64 \pm 10.56$ \\
\hline & Machine washed & $10.73 \pm 2.55$ & $10.47 \pm 1.45$ & $10.95 \pm 2.45$ & $13.45 \pm 3.18$ & $7.76 \pm 0.66$ & $9.04 \pm 0.83$ \\
\hline & Hand washed & $11.29 \pm 2.46$ & $10.74 \pm 1.86$ & $10.69 \pm 1.62$ & $12.93 \pm 2.39$ & $7.35 \pm 0.42$ & $8.34 \pm 10.1$ \\
\hline & Press cake & $10.31 \pm 1.83$ & $11.10 \pm 1.16$ & $10.06 \pm 2.13$ & $13.63 \pm 4.21$ & $6.97 \pm 1.01$ & $8.20 \pm 0.89$ \\
\hline
\end{tabular}




\section{References}

1. Springer, T.L. Biomass yield from an urban landscape. Biomass Bioenergy 2012, 37, 82-87. [CrossRef]

2. Liew, L.N.; Shi, J.; Li, Y. Methane production from solid-state anaerobic digestion of lignocellulosic biomass. Biomass Bioenergy 2012, 46, 125-132. [CrossRef]

3. Prochnow, A.; Heiermann, M.; Plochl, M.; Linke, B.; Idler, C.; Amon, T.; Hobbs, P.J. Bioenergy from permanent grassland-A review: 1. Biogas. Bioresour. Technol. 2009, 100, 4931-4944. [CrossRef] [PubMed]

4. Piepenschneider, M.; Bühle, L.; Wachendorf, M. Solid Fuel Generation from Urban Leaf Litter in Mixture with Grass Cuttings: Chemical Composition, Energetic Characteristics, and Impact of Preprocessing. Bioener. Res. 2016, 9, 57-66. [CrossRef]

5. Khalsa, J.H.A.; Döhling, F.; Berger, F. Foliage and Grass as Fuel Pellets-Small Scale Combustion of Washed and Mechanically Leached Biomass. Energies 2016, 9, 361. [CrossRef]

6. Martin, I.; Roberts, J.; Griffiths, E. Leaf Litter in Street Sweepings: Investigation into Collection and Treatment; Environment Agency: Bristol, UK, 2013. Available online: https://www.gov.uk/government/publications/ leaf-litter-in-street-sweepings-investigation-into-collection-and-treatment (accessed on 2 September 2016).

7. Van Loo, S.; Koppejan, J. The Handbook of Combustion and Co-Firing; Earthscan: London, UK, 2008.

8. Nunes, L.J.R.; Matias, J.C.O.; Catalão, J.P.S. Biomass combustion systems. A review on the physical and chemical properties of the ashes. Renew. Sustain. Energy Rev. 2016, 53, 235-242. [CrossRef]

9. Cherney, J.H.; Verma, V.K. Grass pellet Quality Index: A tool to evaluate suitability of grass pellets for small scale combustion systems. Appl. Energy 2013, 103, 679-684. [CrossRef]

10. DIN Deutsches Institut für Normung e. V. Solid Biofuels. Fuel Specifications and Classes_Part 2: Wood Pellets for Non-Industrial Use (EN 14961-2:2011); Beuth Verlag: Berlin, Germany, 2011.

11. DIN Deutsches Institut für Normung e. V. Solid Biofuels. Fuel Specifications and Classes_Part 6: Non-Woody Pellets for Non-Industrial Use (EN 14961-6:2011); Beuth Verlag: Berlin, Germany, 2011.

12. Obernberger, I.; Brunner, T.; Bärnthaler, G. Chemical properties of solid biofuels-Significance and impact. Biomass Bioenergy 2006, 30, 973-982. [CrossRef]

13. Wachendorf, M.; Richter, F.; Fricke, T.; Graß, R.; Neff, R. Utilization of semi-natural grassland through integrated generation of solid fuel and biogas from biomass. I. Effects of hydrothermal conditioning and mechanical dehydration on mass flows of organic and mineral plant compounds, and nutrient balances. Grass Forage Sci. 2009, 64, 132-143. [CrossRef]

14. Hensgen, F.; Bühle, L.; Donnison, I.; Fraser, M.; Vale, J.; Corton, J.; Heinsoo, K.; Melts, I.; Wachendorf, M. Mineral concentrations in solid fuels from European semi-natural grasslands after hydrothermal conditioning and subsequent mechanical dehydration. Bioresour. Technol. 2012, 118, 332-342. [CrossRef] [PubMed]

15. Hensgen, F.; Richter, F.; Wachendorf, M. Integrated generation of solid fuel and biogas from green cut material from landscape conservation and private households. Bioresour. Technol. 2011, 102, 10441-10450. [CrossRef] [PubMed]

16. Friedl, A.; Padouvas, E.; Rotter, H.; Varmuza, K. Prediction of heating values of biomass fuel from elemental composition. Anal. Chim. Acta 2005, 544, 191-198. [CrossRef]

17. Hartmann, H. Brennstoffzusammensetzung und-eigenschaften (Composition and characteristics of fuels). In Energie aus Biomasse: Grundlagen, Techniken und Verfahren, 2nd ed.; Kaltschmitt, M., Hartmann, H., Hofbauer, H., Eds.; Springer: Berlin, Germany, 2009; pp. 333-374.

18. R Development Core Team. R: A Language and Environment for Statistical Computing; R Foundation for Statistical Computing: Vienna, Austria, 2011.

19. Piepenschneider, M.; Nurmatov, N.; Bühle, L.; Hensgen, F.; Wachendorf, M. Chemical Properties and Ash Slagging Characteristics of Solid Fuels from Urban Leaf Litter. Waste Biomass Valor. 2016, 7, 625-633. [CrossRef]

20. Tyler, G. Changes in the concentrations of major, minor and rare-earth elements during leaf senescence and decomposition in a Fagus sylvatica forest. For. Ecol. Manag. 2005, 206, 167-177. [CrossRef]

21. Bühle, L.; Dürl, G.; Hensgen, F.; Urban, A.; Wachendorf, M. Effects of hydrothermal conditioning and mechanical dewatering on ash melting behaviour of solid fuel produced from European semi-natural grasslands. Fuel 2014, 118, 123-129. [CrossRef] 
22. Steenari, B.M.; Lundberg, A.; Pettersson, H.; Wilewska-Bien, M.; Andersson, D. Investigation of ash sintering during combustion of agricultural residues and the effect of additives. Energy Fuels 2009, 23, 5655-5662. [CrossRef]

23. Sommersacher, P.; Brunner, T.; Obernberger, I. Fuel indexes: A novel method for the evaluation of relevant combustion properties of new biomass fuels. Energy Fuels 2012, 26, 380-390. [CrossRef]

24. Bühle, L.; Hensgen, F.; Donnison, I.; Heinsoo, K.; Wachendorf, M. Life cycle assessment of the integrated generation of solid fuel and biogas from biomass (IFBB) in comparison to different energy recovery, animal-based and non-refining management systems. Bioresour. Technol. 2012, 111, 230-239. [CrossRef] [PubMed]

25. Nussbaumer, T. Combustion on Co-Combustion of Biomass: Fundamentals, Technologies, and Primary Measures for Emission Reduction. Energy Fuels 2003, 17, 1510-1521. [CrossRef]

26. Salzmann, R.; Nussbaumer, T. Fuel Staging for $\mathrm{NO}_{\mathrm{x}}$ Reduction in Biomass Combustion: Experiments and Modelling. Energy Fuels 2001, 15, 575-582. [CrossRef]

(C) 2016 by the authors; licensee MDPI, Basel, Switzerland. This article is an open access article distributed under the terms and conditions of the Creative Commons Attribution (CC-BY) license (http://creativecommons.org/licenses/by/4.0/). 